\title{
Subungual mass index finger
}

\author{
Ning C. McKenzie ${ }^{1} \cdot$ Brandon T. Larsen ${ }^{2} \cdot$ Shelley S. Noland ${ }^{2}$
}

Received: 20 July 2021 / Revised: 18 September 2021 / Accepted: 23 September 2021 / Published online: 7 October 2021 (c) ISS 2021

Originally described by Fetch in 2001 [1], acral fibromyxoma is defined by the World Health Organization as a benign fibroblastic neoplasm with potential for local recurrence and a marked predilection for the subungual and periungual regions of the hands and feet [2]. Also known as superficial acral fibromyxoma, the lesion arises in the dermis and subcutis as a lobulated mass and may rarely affect other areas of the distal extremities, such as the ankle, leg, heel, or palm $[1,2]$. It has been reported in those from the 1 st to 9 th decades of life, but most frequently diagnosed in middle-aged to mature adults (40-60 years), typically presenting with a slowly growing, well-circumscribed mass [3]. The lesion demonstrates a local recurrence rate of 10-24\%, underscoring the importance of complete surgical resection [3, 4] due to its potential for infiltrative growth [2].

There are a limited number of reports detailing the imaging features of acral fibromyxoma. MR imaging characteristically demonstrates a decreased to intermediate signal intensity on T1-weighted images [5-9]. On fluid-sensitive sequences, the lesion signal intensity is more variable, most often showing an intermediate to high signal intensity, reflecting variations in the tumors' fibromyxoid morphology consisting of spindle cells within a myxoid and collagenous (fibrous) stroma [5, 7-9]. Limited reports have described septal and peripheral, as well as delayed central enhancement $[5,9]$.

From the clinical photographs (Fig. 1) and labeled axial STIR image (Fig. 7 ), the lesion can be seen below the nail

Diagnosis: Acral fibromyxoma

The case presentation can be found at https://doi.org/10.1007/ s00256-021-03925-2.

Ning C. McKenzie

mckenzie.ning@mayo.edu

1 Mayo Clinic Alix School of Medicine, 13400 East Shea Boulevard, Scottsdale, AZ 85259, USA

2 Mayo Clinic Arizona, 5777 East Mayo Boulevard, Phoenix, AZ 85054, USA bed along the posterior and lateral nail fold and inhibiting nail growth adjacent to it. As described in other acral fibromyxomas [5, 6, 8, 9], there is osseous remodeling of the distal phalanx secondary to mass effect on the bone with deep scalloping of the radial cortex and mild scalloping of the dorsal cortex (Fig. 2). There is no periosteal reaction, which is consistent with the patient's history of a slow-growing tumor. Representative photomicrographs of the resected tumor show an unencapsulated nodular lesion (arrows in Fig. 8) in the dermis of acral skin, composed of (Fig. 5b) cytologically bland fibroblasts embedded within the variably collagenous and myxoid stroma, without mitotic activity or necrosis. Immunohistochemistry shows positive brown staining of the lesional cells for CD34 (Fig. 6), but no staining for EMA, SMA, desmin, SOX10, or S100 protein (not shown), excluding a variety of other epithelial, melanocytic, myoepithelial, smooth muscle, and myofibroblastic spindle cell neoplasms. Taken together, the histopathologic findings are diagnostic of superficial acral fibromyxoma.

The general differential diagnosis of subungual and periungual masses would include many benign lesions, such as glomus tumor, subungual exostosis, ganglion cyst, epidermal inclusion cyst, soft tissue chondroma, mucoid cyst, and chronic nail bed infection with metaplastic fibro-osseous tissue. Additionally, one should consider malignancies, such as spindle cell melanoma, spindling squamous cell carcinoma, and acral metastasis either as the first presentation or from pre-existing cancer [10]. Most of these differential considerations are readily dismissed when the clinical presentation and imaging characteristics reflecting lesion morphology are considered; however, there are still limited differential considerations. The most common of these is the mucoid cyst. Most mucoid cysts involving the distal finger arise from osteoarthritic changes at the adjacent interphalangeal joint and are characterized by a connecting pedicle to the interphalangeal joint [10], which can be difficult to identify in many cases. The more heterogeneous increased signal from the myxoid and collagenous (fibrous) stroma in the acral fibromyxoma is a more reliable distinguishing feature, which is well demonstrated in this case. Soft tissue chondroma, 


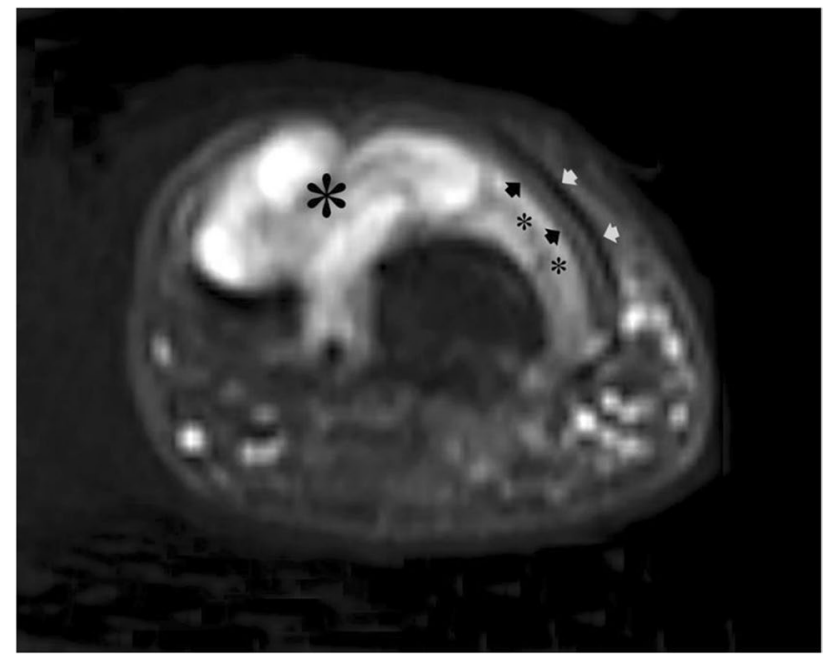

Fig. 7 Axial STIR image shows the tumor (large asterisk) arising within the dermis deep to the nail bed (small asterisks), deforming the nail plate (white arrow) and ventral nail matrix (black arrows)

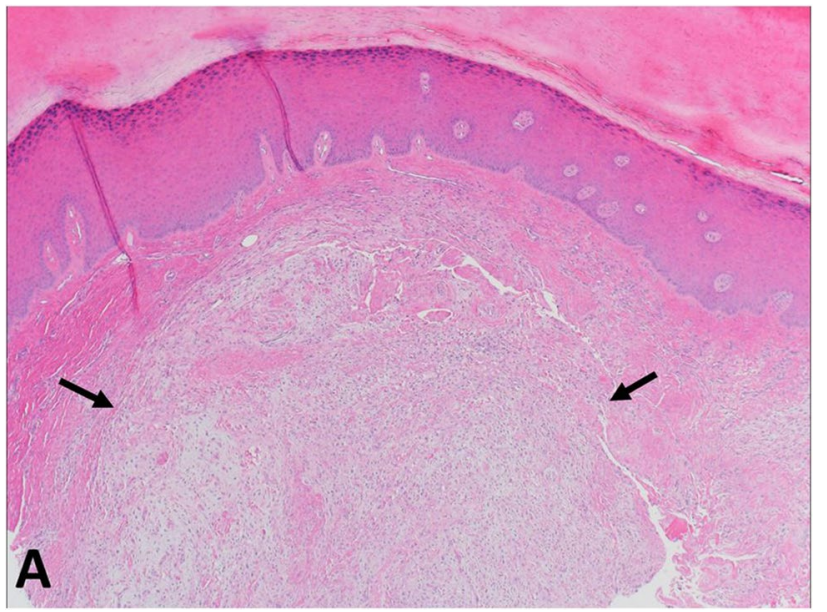

Fig.8 Low-power photomicrograph shows an unencapsulated nodular lesion (arrows) in the dermis of acral skin. Hematoxylin and eosin, $40 \mathrm{x}$

which is a relatively rare lesion, is also most common in the finger with this location accounting for more than half of all cases. Patients present with a slowly growing, lobulated, soft tissue mass involving the fingers, but these are more often associated with periosteum, joint capsule, and tendon sheaths, in contrast to the dermis and subcutis, and mineralization, reported in up to $70 \%$ of cases [10].
Typical treatment for an acral fibromyxoma is surgical excision, and this patient has undergone a local excision with intact finger motion with no pain post-operatively. Recognition of a cyst-like mass with a heterogenous collagenous and fluid-like signal on MRI will allow radiologists to suggest the diagnosis of acral fibromyxoma when encountering subungual and periungual growths.

\section{Declarations}

Conflict of interest The authors declare no competing interests.

\section{References}

1. Fetsch JF, Laskin WB, Miettinen M. Superficial acral fibromyxoma: a clinicopathologic and immunohistochemical analysis of 37 cases of a distinctive soft tissue tumor with a predilection for the fingers and toes. Hum Pathol. 2001;32(7):704-14.

2. Brenn T, Agaimy A, Hollmann TJ. Acral fibromyxoma. In: Lokuhetty D, White VA, Cree IA, editors. WHO classification of tumors. 5th ed. Lyon: International Agency for Research on Cancer; 2020. p. 86-7.

3. Hollmann TJ, Bovee JV, Fletcher CD. Digital fibromyxoma (superficial acral fibromyxoma): a detailed characterization of 124 cases. Am J Surg Pathol. 2012;36(6):789-98.

4. Crepaldi BE, Soares RD, Silveira FD, Taira RI, Hirakawa CK, Matsumoto MH. Superficial acral fibromyxoma: literature review. Rev Bras Ortop (Sao Paulo). 2019;54(5):491-6.

5. Lee S, Reid MAR. Superficial acral fibromyxoma: a case report with radiological review. Skeletal Radiol. 2018;47(7):1021-8.

6. Oteo-Alvaro A, Meizoso T, Scarpellini A, Ballestin C, PerezEspejo G. Superficial acral fibromyxoma of the toe, with erosion of the distal phalanx. A clinical report. Arch Orthop Trauma Surg. 2008;128(3):271-4.

7. Sundaramurthy N, Parthasarathy J, Mahipathy SRRV, Durairaj AR. Superficial acral fibromyxoma: a rare entity - a case report. J Clin Diagn Res. 2016;10(9):PD03-5.

8. Varikatt W, Soper J, Simmons G, Dave C, Munk J, Bonar F. Superficial acral fibromyxoma: a report of two cases with radiological findings. Skeletal Radiol. 2008;37(6):499-503.

9. Bindra J, Doherty M, Hunter JC. Superficial acral fibromyxoma Radiol Case Rep. 2012;7(3):751.

10. Baek HJ, Lee SJ, Cho KH, et al. Subungual tumors: clinicopathologic correlation with US and MR imaging findings. Radiographics. 2010;30(6):1621-36.

Publisher's note Springer Nature remains neutral with regard to jurisdictional claims in published maps and institutional affiliations. 